\title{
Collusion Between Supervision Unit and Contractor in Construction Pro- ject Based on Evolutionary Game Theory
}

\author{
Shiping Wen, Guangdong $\mathrm{Wu}^{*}$ and Yanyan Miao
}

School of Tourism and Urban Management, Jiangxi University of Finance \& Economics, Nanchang, Jiangxi, China, 330013

\begin{abstract}
The behavioral strategy option of project-based organizations directly influences the quality of construction project. Based on the behavioral game model for the owner, supervision unit and contractor, and analysis of mixed strategy Nash equilibrium for the model, under the analysis framework that project-based organizations' bounded rationality, this paper treats the supervision unit and contractor as a benefit community, the benefits matrix was constructed for the owner and community, and analyzed the interaction mechanism and stable state between them with evolutionary game theory. The results shows that, in the evolutionary game system constituted with the owner and community, the stable state of construction project agent collusion is related to certain critical factors including the benefit and loss for collusion behavior, the supervision cost for the owner, the punishment rate from the owner and etc., and affected by the strategy option of counter-player and original state of the game system. Finally, several measures for prevent agents' collusion are proposed.
\end{abstract}

Keywords: Construction project, collusion behavior, evolutionary game, agent.

\section{INTRODUCTION}

In recent years, the total value of outputs of China construction industry with more than $20 \%$ of the annual rate to rapid grow, especially in 2012, it's 13.5303 trillion RMB. In the same year, construction workers reached 38.5247 million people [1]. However, with the rapid development of construction industry; the safety of Construction engineering is terribly worrying. For example, In 2012, just only building municipal engineering of China have occurred total 487 safety accidents and killed 624 people[2],It is closely related with the confusion of Chinese construction market order and the lack of credit between the main body. In the implementation of construction projects, the owner, supervision unit and contractor is the most active factor in the project, the opportunistic behavior of any one party will have a significant impact on the project. In traditional project management mode, the principal-agent relationship between owner and contractor is identified by Engineering contractors contract and supervision contract between the owner and supervision company is determined by the principal-agent relationship, yet, the relationship between supervision and the contractor is a kind of supervision and being supervised [3] (Fig. 1). However, the contractors know more information about the private information about the project than the owner to some extent. In the concept of self-interest driven, then, the contractors may be rent-seeking to the owners. In order to obtain the contractor's personal information conveniently, at the same time, the owners who are information disadvantage are taking on supervision unit to monitor the contractor [4]. With

*Address correspondence to this author at the School of Tourism and Urban Management, Jiangxi University of Finance \& Economics, Nanchang, Jiangxi, China, 330013 the development of the construction industry, increasingly fierce the market competition, also squeezing the supervision unit and contractor's profit space to some degree. As an independent operation, self-sustaining economic entity, the essential attribute of contractors and supervision units is pursuit the maximization of interests. Therefore, these which can be regarded as a risk-neutral "broker" to a certain extent, then the contractor and supervisory board will be determined their own behavior in the process of project construction according to the results of the cost-benefit analysis.

As an independent third party to the principal-agent and because of majority of the supervision contract are fixed compensation systems, the supervision units cannot earn profits from the project construction, even though hard work also won't get extra income, That led to the lazy, ineffective supervision and even collusion motivation objectively. Supervision units own the right of construction supervision and acceptance, as a rational broker, so as to pursue their own maximum profit; they will use their right of engineering supervision, check and acceptance to the contractors rentseeking [5]. The rapid development of the construction industry in recent years has leaded to the increase in the number of registered project engineering consultant was far lower than the construction industry total value of output increase, apparently, the shortage of supervision personnel is exacerbated the occurrence of this phenomenon [6]. As direct implementers of the project, compare to the owners, the contractor is in a subordinate position. Because of the construction market competition is intense and low concentration, service supply and demand is in a state of a buyer's market, especially the bidding mechanism of low bid, all of these are motivated the contractors to reduce the project construction cost to pursue interests, and to achieve this purpose, 


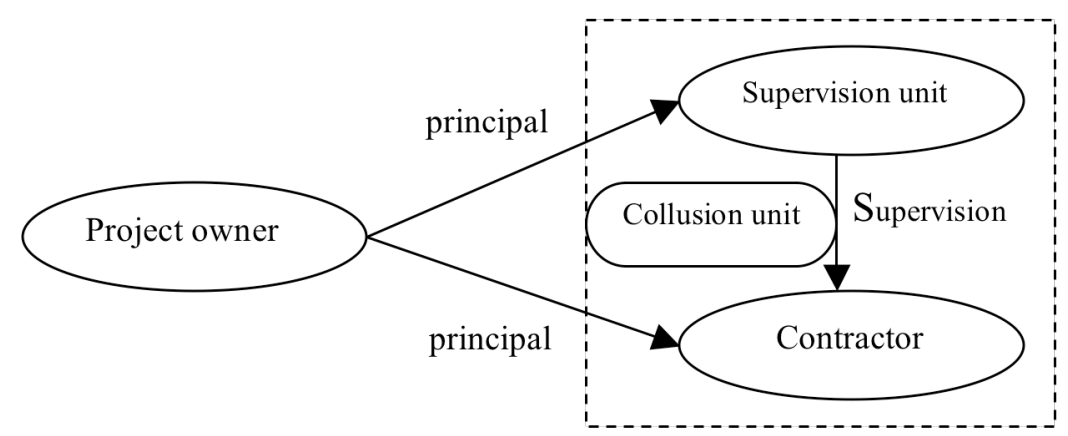

Fig. (1). Construction projects in the main body the relationship between the three parties.

it must be collusion with supervision units. Therefore, the construction of information asymmetry between the main body in the process of project implementation is the precondition of contractors and supervision units of collusion to implemented, and the pursuit of interests is the spontaneity of motivation that trigger supervision company and contractor to collude.

Currently, there have been many literatures used game theory to research the collusion behavior between construction project agents. Yin (2012) established a game model that based on contract management to analyze the causes of contractors and design units' collusion and work out the standards of determination and processing [7]. Shao and Wang (2011) analyzed the existence condition that collusion occurred between supervision and contractor and also the object take by the owners [8]. Yu and Zhang (2008) based on the analysis of the principal-agent relationship of government project, established the owner, contractor and supervision units tripartite game model of collusion [9]. Yang and Wang (2006) based on the phenomenon that conspiracy to strike state funds in the large infrastructure project of the owner, the construction and quality supervision party, and given us the game analysis of each unit in the project construction, and also put forward the occurred conditions and prevention measures of collusion [10]. Guo (2008) analyzed the game model of construction market of the principal supervisor agent and believes the occurrence of collusion behavior of the construction market can be reduced through the way of design the supervision reward incentive mechanism; improve the collusion probability and son on [11]. Throughout the literatures above all, there is few subject research to explore the collusion of main body of construction project by using evolutionary game, but in other main body behavior has been existed applications. For example, Cheng and Chen (2011) aimed at the process of construction engineering safety supervision by using evolutionary game, and analyzed the interactive behavior and stable state between the choice of construction enterprise safety production strategy and the choice of government supervision department regulation strategy [12]; Zhou et al. (2012) introduced the prospect theory in the process of evolutionary game, built an income perception matrix that different from the traditional income matrix, analyzed the construction safety management behavior[13]. The premise of these research hypotheses is that the construction project agent is not entirely rational but limited rationality and the agent's behavior choice is a dynamic change, the agent keep learning from each other through trial and error and option a strategy that is benefit for their own development. Combining with the evolutionary game in other behavior research of the construction project agent, it will be more suitable for the practice characteristic of construction project by using evolutionary game theory to study the strategy choice of construction project agent collusion behavior. Therefore, in this paper, we will on the basis of the existing literatures, combining the influence factors and process of construction project agent collusion behavior, built an income matrix based on the premise that the construction project agents are limited rationality and then has an evolutionary game analysis on collusion behavior, discussed the evolution rules of game action of both sides in a perspective of dynamic and provided decision-making reference for building long-term prevention mechanism of construction project agent collusion.

\section{GAME MODEL FOR CONSTRUCTION PROJECTS SUBJECT TRIPARTITE - BASED ON THE ANALY- SIS OF CLASSIC GAME}

\subsection{Research Hypothesis and Model Building}

(1) For the supervision units, every specific project has a reasonable profit and it can be roughly calculated by the contract price $R_{j}$ subtract the supervision $\operatorname{cost} C_{j}$, supervision cost includes the basic salary of personnel, allowances, welfare, various fee for equipment purchase - maintenance royalty and various kinds of office expenses, etc. Assume supervision units in the case of the normal operation and the profit is $R_{j}-C_{j}$.

(2) For the contractors, assume the bid price is $T_{c}$, the construction cost of normal operation situation is $C_{c}$, and then the actual profit is $T_{c}-C_{c}$.

(3) If the supervision conspired with the contractors, then the regulation of contractor operations will be relaxed by the supervision at this moment and it can reduce a certain supervision cost accordingly, set it to $F_{j}$. The contractor will reduce the engineering quality through the method of shoddy and cut corners, assume construction cost can be saved. Assume the distribution ratio that the contractor render to supervision is $\eta$.

(4) If the supervision units conspired with the contractors, the loss of the owner will be $R_{0}$, so the owner will monitor the collusion behavior of agent, assume the regulatory costs of the owners are $C_{y}$. When the owners participate in 
Table 1. The game income matrix of Construction project tripartite.

\begin{tabular}{|c|c|c|c|}
\hline & & Supervision & No supervision \\
\hline \multirow{6}{*}{$\begin{array}{l}\text { Supervision unit } \\
\text { and the contractor }\end{array}$} & \multirow{3}{*}{ Collusion } & $\alpha\left(R_{j}-C_{j}\right)+\beta\left(T_{c}-C_{c}\right)-C_{y}-R_{0}$ & $-R_{0}$ \\
\hline & & $(1-\alpha)\left(R_{j}-C_{j}\right)+F_{j}+\eta C$ & $R_{j}-C_{j}+F_{j}+\eta C$ \\
\hline & & $(1-\beta)\left(T_{c}-C_{c}\right)+(1-\eta) C$ & $T_{c}-C_{c}+(1-\eta) C$ \\
\hline & \multirow{3}{*}{ No collusion } & $-C_{y}$ & 0 \\
\hline & & $R_{j}-C_{j}$ & $R_{j}-C_{j}$ \\
\hline & & $T_{c}-C_{c}$ & $T_{c}-C_{c}$ \\
\hline
\end{tabular}

the regulation and the supervision conspired with the contractor, supervision of the owner is very effective, as long as there is a conspiracy, the owners will be able to find and punish the supervision units and contractors, assume it is $\alpha$ and $\beta$ times of normal income. Namely $\alpha\left(R_{j}-C_{j}\right)$ and $\beta\left(T_{c}-C_{c}\right)$

(5) Assume the proportion that supervision unit and the contractor determined collusion or not is $\mathrm{x}$ and $1-x$, the owner determined supervision or not is $y$ and $1-y$.

According to that, the constructed game income matrix between the owner, supervision unit and contractors is following:

\subsection{The Solution and Analysis of Model}

There is no pure strategy Nash Equilibrium in above game, so the only way is to solve the mixed strategy Nash Equilibrium [14 15].

(1) The expected revenue, expressed by $U_{1}, U_{2}$ respectively, the owner choose supervision strategy and no supervision strategy can be defined as following:

$$
U_{1}=x\left[\alpha\left(R_{j}-C_{j}\right)+\beta\left(T_{c}-C_{c}\right)-R_{0}\right]-C_{y} U_{2}=-x R_{0}
$$

When the owner chooses supervision strategy or no supervision strategy is no difference, namely $U_{1}=U_{2}$, and solved $\mathrm{x}$ we can get:

$$
x^{1}=\frac{C_{y}}{\alpha\left(R_{j}-C_{j}\right)+\beta\left(T_{c}-C_{c}\right)}
$$

It means when the probability that the supervision unit conspire with the contractor is less than $x^{1}$, the optimal strategy of the owner is no supervision. On the contrary, when the probability that the supervision unit conspire with the contractor is more than $x^{1}$, the optimal strategy of the owner is supervision.

(2) The expected revenue, expressed by $V_{1}, V_{2}$ respectively, supervision unit choose collusion strategy and no collusion strategy can be defined as following:

$$
V_{1}=(1-\alpha y)\left(R_{j}-C_{j}\right)+F_{j}+\eta C
$$

$$
V_{2}=R_{j}-C_{j}
$$

When supervision unit chooses collusion strategy or no collusion strategy is no difference, namely $V_{1}=V_{2}$, and solved y we can get:

$$
y^{1}=\frac{F_{j}+\eta C}{\alpha\left(R_{j}-C_{j}\right)}
$$

It means when the probability that the owner choose supervision strategy is less than $y^{1}$, the optimal strategy of supervision unit is collusion. On the contrary, when the probability that the owner choose supervision strategy is more than $y^{1}$, the optimal strategy of supervision unit is no collusion.

(3) The expected revenue, expressed by $P_{1}, P_{2}$ respectively, the contractor choose collusion strategy and no collusion strategy can be defined as following:

$$
\begin{aligned}
& P_{1}=(1-\beta y)\left(T_{c}-C_{c}\right)+(1-\eta) C \\
& P_{2}=T_{c}-C_{c}
\end{aligned}
$$

When the contractor chooses collusion strategy or no collusion strategy is no difference, namely $P_{1}=P_{2}$, and solved y we can get:

$$
y^{2}=\frac{(1-\eta) C}{\beta\left(T_{c}-C_{c}\right)}
$$

It means when the probability that the owner choose supervision strategy is less than $y^{2}$, the optimal strategy of the contractor is collusion. On the contrary, when the probability that the owner choose supervision strategy is more than $y^{2}$, the optimal strategy of the contractor is no collusion.

\section{GAME MODEL FOR CONSTRUCTION PROJECTS SUBJECT TRIPARTITE - BASED ON THE ANALY- SIS OF EVOLUTIONARY GAME}

\subsection{The Hypothesis and Establishment of Model}

Although the relationship between supervision unit and the contractor is supervising and being supervised, because it 
Table 2. The game income matrix of Construction project tripartite.

\begin{tabular}{|c|c|c|c|}
\hline & & Supervision & No supervision \\
\hline \multirow{4}{*}{$\begin{array}{l}\text { Supervision unit } \\
\text { and the contrac- } \\
\text { tor }\end{array}$} & \multirow{2}{*}{ Collusion } & $\alpha\left(R_{j}-C_{j}\right)+\beta\left(T_{c}-C_{c}\right)-C_{y}-R_{0}$ & $-R_{0}$ \\
\hline & & $(1-\alpha)\left(R_{j}-C_{j}\right)+(1-\beta)\left(T_{C}-C_{C}\right)+F_{j}+C$ & $R_{j}-C_{j}+T_{c}-C_{C}+F_{j}+C$ \\
\hline & \multirow{2}{*}{ No collusion } & $-C_{y}$ & 0 \\
\hline & & $R_{j}-C_{j}+T_{c}-C_{c}$ & $R_{j}-C_{j}+T_{c}-C_{c}$ \\
\hline
\end{tabular}

is need to communicate and collaborate with each other, then this long-term contact makes it possible for one party invite other party to collude. Therefore, it is easy to reach some sort of agreements between supervision unit and the contractors, and then relax the supervision to the contractors appropriately. In this case, not only the contractors can save construction costs, the supervision unit will also be able to save supervision costs and get appropriate returns from the contractors. According to Shao and Wang (2011), we know that under the condition of asymmetric information, unless the contractors to prosecute the collusion invitation from supervision unit, or even if the supervision unit cannot get the profit from the contractors, the supervision unit still will desire to collude. However, the optimal strategy for the contractor at this moment is to accept collusion invitation from supervision unit. Because the construction market reputation mechanism of our country is incomplete currently, the contractors have no enough motivation to disclose the collusion invitation from supervision unit. Additionally, even if the owners are not satisfied with the work of supervision unit in the project practice, without significant engineering quality accidents and safety accident, the owner is also not willing to have a lawsuit against supervision unit at the cost of high costs and expected benefits delayed. Therefore, we can regard the supervision unit and the contractors as a community interest to choose collusion strategy or not at the same time. In this case, the owner still has two strategies to choose, namely supervision and no supervision. Adding the interest of supervision unit and the contractors, and then made the following Table:

According to the game relation show in the chart 2, we can build the Replicator Dynamics Equation of construction safety management behavior. Assuming the proportion that construction personnel comply with safety regulations operating strategy and not is $\mathrm{x}$ and $1-\mathrm{x}$ respectively, the proportion that the safety management personnel determine to supervise and not is y and1-y respectively. Then, the expected revenue, noted by $U_{1}$ and $U_{2}$ respectively, the owner choose supervision strategy and no supervision strategy, and the average expected return $\bar{U}$ can be defined as following:

$$
\left.\begin{array}{l}
U_{1}=x\left[\alpha\left(R_{j}-C_{j}\right)+\beta\left(T_{c}-C_{c}\right)-R_{0}\right]-C_{y} \\
U_{2}=-x R_{0} \\
\bar{U}=x y\left[\alpha\left(R_{j}-C_{j}\right)+\beta\left(T_{c}-C_{c}\right)\right]-y C_{y}-x R_{0}
\end{array}\right\}
$$

In the same way, the expected returns that supervision unit and the contractors choose collusion or not, noted by $V_{1}+P_{1}$ and $V_{2}+P_{2}$ respectively, and the average expected return $\overline{V+P}$ can be defined as following:

$$
\left.\begin{array}{l}
V_{1}+P_{1}=(1-\alpha y)\left(R_{j}-C_{j}\right)+(1-\beta y)\left(T_{c}-C_{c}\right)+F_{j}+C \\
V_{2}+P_{2}=R_{j}-C_{j}+T_{c}-C_{c} \\
\overline{V+P}=(1-\alpha x y)\left(R_{j}-C_{j}\right)+(1-\beta x y)\left(T_{c}-C_{c}\right)+x\left(F_{j}+C\right)
\end{array}\right\}
$$

Using the Malthusian replicator dynamics evolution equation, we can get the replicator dynamics equation of $x$ and $y$, listed as following:

$$
\begin{aligned}
& F(x)=\frac{d x}{d t}=x(1-x)\left[-\alpha y\left(R_{j}-C_{j}\right)-\beta y\left(T_{c}-C_{c}\right)+F_{j}+C\right] \\
& F(y)=\frac{d y}{d t}=y(1-y)\left[\alpha x\left(R_{j}-C_{j}\right)+\beta x\left(T_{c}-C_{c}\right)-C_{y}\right]
\end{aligned}
$$

\subsection{The Solution and Analysis of Model}

(1) The stable strategy analysis of supervision unit and the contractors

$$
\text { When } y_{D}=\frac{F_{j}+C}{\alpha\left(R_{j}-C_{j}\right)+\beta\left(T_{c}-C_{c}\right)} \text { (The equality hold up only }
$$
if $\left.F_{j}+C \leq \alpha\left(R_{j}-C_{j}\right)+\beta\left(T_{c}-C_{c}\right)\right)$ the value of Equation (1) is 0 , indicate all $x$ is a stable state. When $y_{D} \neq \frac{F_{j}+C}{\alpha\left(R_{j}-C_{j}\right)+\beta\left(T_{c}-C_{c}\right)}$, let $F(x)=0$, then we can get two possible steady states, namely $x_{1}^{*}=0$ and $x_{2}^{*}=1$. Now, we can analyze the evolution steady state of supervision unit and the contractors according to the symbol of $F^{\prime}\left(x^{*}\right)$.
If $y_{D}>\frac{F_{j}+C}{\alpha\left(R_{j}-C_{j}\right)+\beta\left(T_{c}-C_{c}\right)}$,
$-\alpha y\left(R_{j}-C_{j}\right)-\beta y\left(T_{c}-C_{c}\right)+F_{j}+C<0, F^{\prime}\left(x_{1}^{*}\right)<0$ and $x_{1}^{*}=0$ is the evolution steady state, the supervision unit and the contractors will not choose the collusion strategy at this time. If $y_{D}<\frac{F_{j}+C}{\alpha\left(R_{j}-C_{j}\right)+\beta\left(T_{c}-C_{c}\right)}$, then $-\alpha y\left(R_{j}-C_{j}\right)-\beta y\left(T_{c}-C_{c}\right)+F_{j}+C>0, \quad F^{\prime}\left(x_{2}{ }^{*}\right)<0$ and $x_{2}^{*}=1$ is the evolution steady state, the supervision unit and the contractors will choose the collusion strategy at this time.

(2) The stable strategy analysis of the owners 
Table 3. The stability analysis of equilibrium.

\begin{tabular}{|c|c|c|c|c|}
\hline Equilibriums & $\operatorname{det} J$ & Sign & $\operatorname{tr} J$ & Sign \\
\hline \hline$(0,0)$ & $C_{y}\left(F_{j}+C\right)$ & + & $F_{j}+C-C_{y}$ & \\
\hline$(0,1)$ & $-C_{y}\left(F_{j}+C+1\right)$ & - & $F_{j}+C+C_{y}-\alpha\left(R_{j}-C_{j}\right)-\beta\left(T_{c}-C_{c}\right)$ & instability \\
\hline$(1,0)$ & $-\left(1+C_{y}\right)\left(F_{j}+C\right)$ & - & $\alpha\left(R_{j}-C_{j}\right)+\beta\left(T_{c}-C_{c}\right)-F_{j}-C-C_{y}$ & instability \\
\hline$(1,1)$ & $3\left[\alpha\left(R_{j}-C_{j}\right)+\beta\left(T_{c}-C_{c}\right)\right]^{2}+\left[\left(1+C_{y}\right)\left(F_{j}+C\right)+C_{y}\right]$ & + & $C_{y}-F_{j}-C$ & \\
\hline$\left(x_{D}, y_{D}\right)$ & $\backslash$ & $\backslash$ & 0 & 1 \\
\hline
\end{tabular}

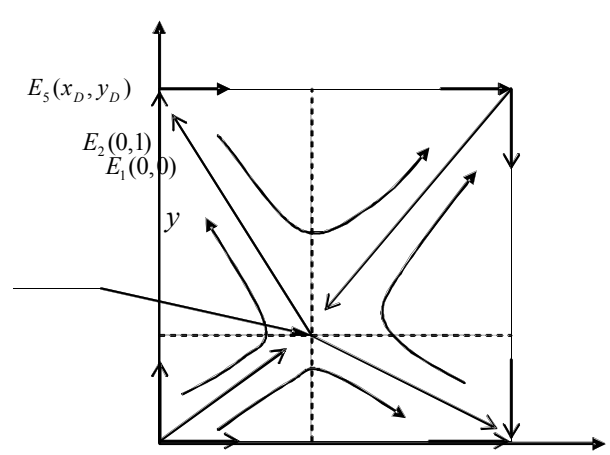

(a) $F_{j}+C-C_{y}>0$

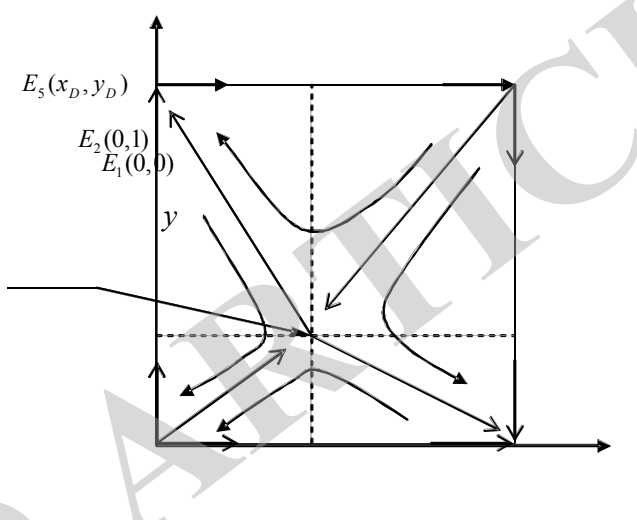

(b) $F_{j}+C-C_{y}<0$

Fig. (2). The evolution phase diagram of construction project agent's collusion behavior.

$$
\text { When } x_{D}=\frac{C_{y}}{\alpha\left(R_{j}-C_{j}\right)+\beta\left(T_{c}-C_{c}\right)} \text { (The equality hold up }
$$

only if $\left.\alpha\left(R_{j}-C_{j}\right)+\beta\left(T_{c}-C_{c}\right)>C_{y}\right)$ the value of Equation (2) is 0 , indicate all $y$ is a stable state. When $x_{D} \neq \frac{C_{y}}{\alpha\left(R_{j}-C_{j}\right)+\beta\left(T_{c}-C_{c}\right)}$, let $F(x)=0$, in the same way, we can get two possible steady states, namely $y_{1}^{*}=0$ and $y_{2}^{*}=1$. Now, we can analyze the evolution steady state of the construction personnel according to the symbol of $F^{\prime}\left(y^{*}\right)$. If $x_{D}>\frac{C_{y}}{\alpha\left(R_{j}-C_{j}\right)+\beta\left(T_{c}-C_{c}\right)}$, then $\alpha x\left(R_{j}-C_{j}\right)+\beta x\left(T_{c}-C_{c}\right)-C_{y}>0, F^{\prime}\left(y_{2}{ }^{*}\right)<0$ and $y_{2}^{*}=1$ is the evolution steady state, the owners will choose the supervision strategy at this time. If $x_{D}<\frac{C_{y}}{\alpha\left(R_{j}-C_{j}\right)+\beta\left(T_{c}-C_{c}\right)}$, then $-\alpha y\left(R_{j}-C_{j}\right)-\beta y\left(T_{c}-C_{c}\right)+F_{j}+C>0, \quad F^{\prime}\left(y_{1}^{*}\right)<0$ and $y_{1}^{*}=0$ is the evolution steady state, the owners will not choose the supervision strategy at this time.

Combining the analysis of (1) and (2), compare with analysis result of classic game model, and can be found that the strategy choices of construction project agent depends on the proportion of the strategy choice of another agent, the agent will make a choice after weigh their own gains and losses, the bigger the loss that caused by strategy choice, the more likely the agent avoid this strategy; However, the big- ger the loss of one agent that caused by behavior choice of another agent, the more likely the agent adopt this strategy. Supervision unit and the contractors, for example, the bigger $F_{j}+C$ and the smaller $\alpha\left(R_{j}-C_{j}\right)+\beta\left(T_{c}-C_{c}\right)$, the more likely the supervision unit and the contractors adopt this strategy.

(3) The stable strategy analysis of the game model for construction projects subject tripartite

The evolution of construction projects subject tripartite can be described by the system that composed of Equation (1) and Equation (2) and the system has 5 equilibriums: $(0,0),(0,1),(1,1),(1,0),\left(x_{D}, y_{D}\right)$. According to Friedman's method, the evolutionary stable strategy (ESS) of differential equation system can be got by the stability analysis of the Jacobian matrix of the system. The determinant of matrix $J$ that built by Equation (1) and Equation (2) and the Trace of matrix are as follows:

$$
\left.\begin{array}{rl}
\operatorname{det} J= & x y(x+y+x y)\left[\alpha\left(R_{j}-C_{j}\right)+\beta\left(T_{c}-C_{c}\right)\right]^{2}+ \\
& +(1-2 x)(1-2 y)\left[\left(x+C_{y}\right)\left(F_{j}+C\right)+y C_{y}\right] \\
\operatorname{tr} J= & (1-2 x)\left[-\alpha y\left(R_{j}-C_{j}\right)-\beta y\left(T_{c}-C_{c}\right)+F_{j}+C\right] \\
& +(1-2 y)\left[\alpha x\left(R_{j}-C_{j}\right)+\beta x\left(T_{c}-C_{c}\right)-C_{y}\right]
\end{array}\right\}
$$

According to the local stability analytical method of Jacobian matrix and having stability analysis to these equilibriums, the consequence is in the Table 3 . 

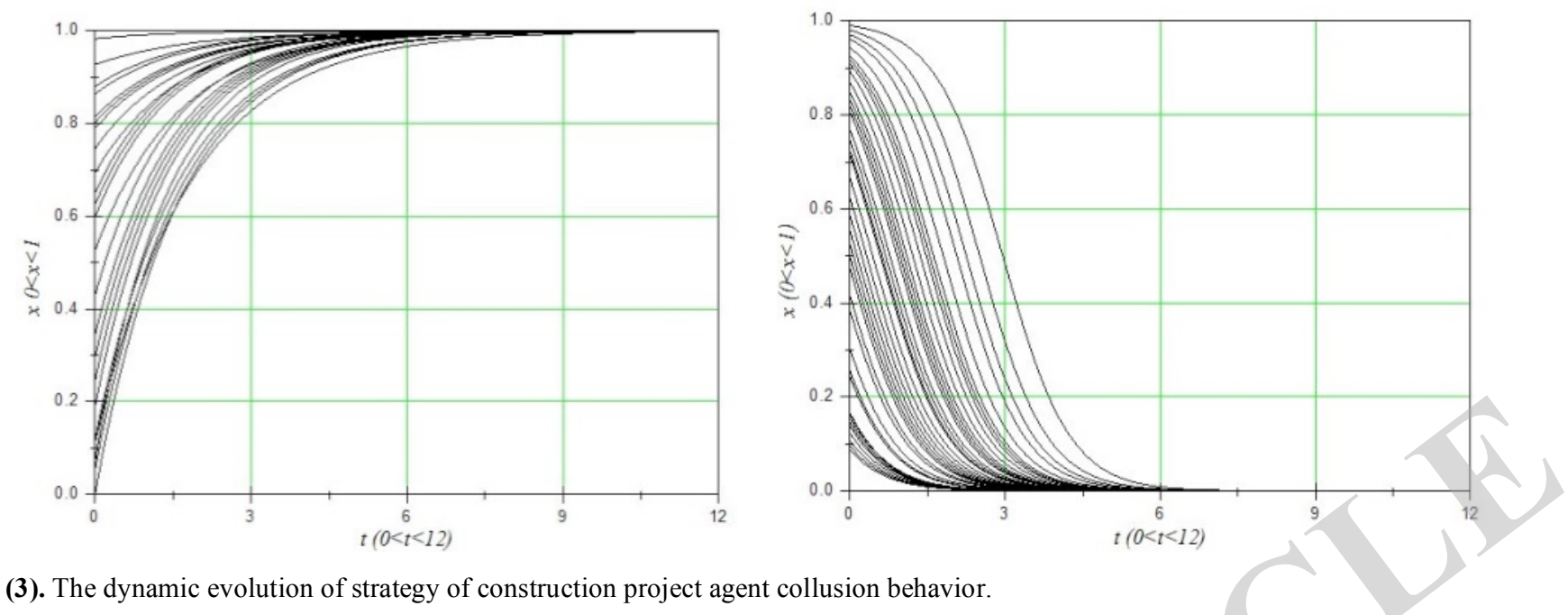

Fig. (3). The dynamic evolution of strategy of construction project agent collusion behavior.

Based on evolutionary game theory, the system's stable point is the equilibriums that satisfied condition $\operatorname{det} J>0$ and $\operatorname{tr} J<0$. Through the chart 3 can be found that the stable point of construction project subject tripartite depends on the sign of $F_{j}+C-C_{y}$. If $F_{j}+C-C_{y}>0$, then $(1,1)$ is the system's evolution stable point; if else $F_{j}+C-C_{y}<0, \quad(0,0)$ is the system's evolution stable point. So the owner game between the supervision and no supervision, supervision unit- the contractors' game between collusion and no collusion, and their expectation adjusted step by step, and formed the process of dynamic game as shown on the surface $S(x, y)$. The surface is intertexture formed between collusion and no collusion, supervision and no supervision. When the income that supervision unit-the contractor take collusion strategy is higher and the supervision costs of the owner is lower, the supervision unit - the contractor will take collusion strategy and the owner will take supervision strategy at this time. On the contrary, when the income that supervision unit-the contractor take collusion strategy is lower and the supervision costs of the owner is higher, the supervision unit - the contractor will take no collusion strategy and the owner will take no supervision strategy. In the two kinds of circumstances above, the E2E3E4E5 zone in the Fig. (2a) can be defined as a collusion - supervision zone, the E1E2E3E5 zone in the Fig. (2b) can be defined as a no collusion - no supervision zone, the proportion of strategy choice depends on the location of saddle point.

The bigger the area of E2E3E4E5 in the Fig. (2a), the greater the proportion that the owner choose supervision strategy and the supervision unit - the contractor choose collusion strategy; the bigger the area of E1E2E3E5 in the Fig. (2b), the greater the proportion that the owner choose no supervision strategy and the supervision unit - the contractor choose no collusion strategy.

\subsection{The Numerical Case and Analysis}

In order to describe the strategy evolution stability analysis of construction project agent collusion behavior intuitively, this article will take the interests community of super- vision unit - the contractor as the object, assign for each index, and using Matlab 2010a to simulate the dynamic evolution process of strategy choice.

(1) The assignment of each index of game payoff matrix is as follows: $T_{c}-C_{c}=100, R_{j}-C_{j}=100, R_{0}=10, \alpha=\beta=1$, $F_{j}=200, C=200$. (a) $C_{y}=50$, at this point, $F_{j}+C-C_{y}>0$, if $y<0.5$, set $y=0.1$, the dynamic evolution process of strategy of construction project agent collusion behavior that change over time, as show in Fig. (3a). From the picture we can see, under different collusion strategy initial probability, the probability that the project agents choose collusion strategy can eventually converges to 1 , and along with the increase of initial probability the convergence speed will also accelerate. That is to say, when the probability that the owner choose "collusion" strategy is reducing, the project agent will eventually take the "collusion" strategy. (b) $C_{y}=500, \quad$ at this point, $F_{j}+C-C_{y}<0, \quad$ if $y>0.5$, set $y=0.7$, the dynamic evolution process of strategy of construction project agent collusion behavior that change over time, as show in Fig. (3b). From the picture we can see, under different collusion strategy initial probability, the probability that the project agents choose "collusion" strategy can eventually converges to 0 , and along with the increase of initial probability the convergence speed will slow yet. That is to say, when the probability that the owner choose supervision strategy is rising, the project agent will eventually take the "no collusion" strategy.

\section{CONCLUSION AND PROSPECT}

Under limited rationality analysis framework, used the evolutionary game theory to analyze the collusion behavior of construction project agent. Research shows that the steady state of construction project agent collusion behavior mainly related to the supervision costs of the owner, the agent's interest that collusion brings to, the owner's loss that collusion causes, the supervision of the owner, etc. The main conclusions are as follows: (1) Supervision unit and the contractor have collusion demand internal, and information asymmetry 
is the premise of this kind of behavior are realized. (2) If there is information asymmetry between the owner and construction project agent, the owner can reduce the probability that collusion behavior generated by intensify supervision; But if there is no information asymmetry between the construction project agents, then the owners cannot reduce the probability that collusion behavior generated by intensify supervision. (3) The comparison between own gains and losses is the basis of the strategy choice of construction project agent and the owner, once a certain strategy can bring greater earnings relatively, then the body will have the urge to choose this strategy. (4) If the owners want to supervise the agent collusion behavior effectively, the effective measure is to reduce their own supervision costs; and the agents want to take the collusion behavior, the effective measure is to improve the income that collusion brings to. Based on the above analysis, if you want to reduce the risk of construction project that the agent collusion behavior brings to, the owner should strengthen the selection and control to the agent, such as bidding priority should be given to the agent's credit level, the project quality and other technical factors. However, from the analysis of collusion behavior game equilibrium, we should create open, fair competition market environment and establish the reputation mechanism, trust mechanism, incentive and constraint mechanism of the construction market, etc. Form a project pattern that the interest of body is coordinate relatively, and then regularize the behavior of construction project main body.

\section{CONFLICT OF INTEREST}

The authors confirm that this article content has no conflict of interest.

\section{ACKNOWLEDGEMENTS}

This work was supported by National Natural Science Funds of China (Grant No. 71301065), University Social Sciences and Humanities Funds of Jiangxi Province (Grant No.JC1309), Scientific and technological research Funds of Department of Education of Jiangxi Province (Grant No. GJJ14341).

\section{REFERENCE}

[1] National Bureau of Statistics of the People's Republic of China, China Statistics Yearbook (2013). Beijing: China Statistics Press, 2012.

[2] Ministry of Housing and Urban-Rural Development of the Republic of China, Housing Municipal Engineering production safety accidents briefing, 2012.

[3] Xiang P.C., Ren H., Zhong Y., Feng Y.B., "The behavior game analysis for participants in construction project based on the theory of information asymmetries," Journal of Chongqing University (Natural Science Edition), Vol. 30, pp.144-151, October, 2007.

[4] L. Jean-Jacques, T. Jean, "Cost padding, auditing and collusion," Annals of Economics and Statistics, Vol.5, pp. 205-226, May, 1992.

[5] Cheng S.P., Ge Q.D., Sheng Z.H., Liu X.F., "A game analysis of the collusion in large construction project under follow-up audit pattern," Forecasting, Vol.31, pp. 34-38, January, 2012

[6] Liu X.J., Guo T., "Research on the problem of project supervisor industry based on game theory," Science \& Technology Progress and Policy, Vol.29, pp. 100-106, August, 2012.

[7] Yin Y.L., Dong Y., Zhang L.Y., "A study on collusion-proof between contractor and design unit in construction engineering," Journal of East China Jiaotong University, Vol. 29, pp. 54-59, January, 2012.

[8] Shao X.S., Wang G.G., ,The study of collusion between supervision and contractor during the course of construction with game," Journal of Northeast Dianli University, Vol. 31, pp.128-130, May, 2011.

[9] Yu X.Z., Zhang H.J., "Collusion game between owner, contractor and supervisor for government construction project," Inquiry into Economic Issues, Vol. 11, pp. 86-92, November, 2008.

[10] Yang Y.H., Wang Y.L., "A game analysis of the collusion of players involved in large construction project," Journal of Industrial Engineering/Engineering Management, Vol.2, pp. 126-129, February, 2006.

[11] Guo N.Y., "Prevention mechanism for construction project agent collusion behavior," Journal of Jiangxi University of Finance and Economics, Vol. 59, pp. 26-29, May, 2008.

[12] Cheng M., Chen H., "Research on construction safety supervision based on evolutionary game theory," Operations and Management Science, Vol. 20, pp. 210-215, June, 2011.

[13] Zhou G.H., Zhang Y., "Evolutionary game analysis of the behavior of construction safety management based on prospect theory." Journal of Systems and Management, Vol. 21, pp. 501-509, April, 2012.

[14] E.R. Smolyakov, "Search for the strongest equilibrium in multiperson games," International Journal of Computer and System Science, Vol. 42, pp. 435-443, March, 2003.

[15] G. Peterson, A. Reif, "Decision algorithms for multiplayer noncooperative games incomplete information," Computers \& Mathematics with Applications, Vol. 43, pp. 179-206, January, 2002.

[16] D. Friedman, "On economic applications of evolutionary game theory," Journal of Evolutionary Economics, Vol. 8, pp. 15-43, January, 1998.

C) Wen et al.; Licensee Bentham Open.

This is an open access article licensed under the terms of the Creative Commons Attribution Non-Commercial License (http://creativecommons.org/licenses/by-nc/3.0/) which permits unrestricted, non-commercial use, distribution and reproduction in any medium, provided the work is properly cited. 